\title{
Dynamics of nutrients in the water of the pelagic zone of Lake Baikal
}

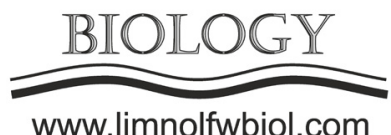

\author{
Domysheva V.M.*, Sakirko M.V., Onischuk N.A., Netsvetaeva O.G, \\ Molozhnikova E.V.
}

Limnological Institute, Siberian Branch of the Russian Academy of Sciences, Ulan-Batorskaya Str., 3, Irkutsk, 664033, Russia

\begin{abstract}
This work discusses the spatial and temporal dynamics of nutrients in the pelagic zone of Lake Baikal to assess the changes in their concentrations and distribution in recent years. The study has revealed that at the end of the summer, phytoplankton almost completely consumes phosphates in the upper layers of water. There is a slight trend towards an increase in the weighted average concentration of nitrates in the water column of the pelagic zone of Lake Baikal.
\end{abstract}

Keywords: Lake Baikal, nitrogen, phosphorus, silicon

\section{Introduction}

Warming and eutrophication of lakes occur throughout the world, and Lake Baikal is no exception. Lake Baikal is unique in depth and volume of water. With an increase in the water temperature in the lake (Shimaraev and Domysheva, 2013) have changed the structure and quantitative parameters of hydrobionts and the chemical composition of water in localized areas of the coastal area (Kravtsova et al., 2012; Timoshkin et al., 2014; Izmest'eva et al., 2016). In the pelagic zone of the lake, the number of small-celled species increased, and the density of the dominant species decreased (Bondarenko et al., 2019). Due to these changes, the issue concerning the trends towards the changes in the concentration of nutrients in the deep part of Lake Baikal has now become much more relevant. This study aims to analyse the changes in the concentration and distribution of nutrients, which have occurred in recent years.

\section{Material and methods.}

In this study, we used the data on hydrochemical studies of 20 stations (10-16 layers from the surface to the near-bottom area) of the longitudinal section in the pelagic zone of the lake in late May and June from 2007 to 2019 as well as in late July and September from 2018 to 2019. Samples for the determination of nutrients were filtered using cellulose acetate membrane filters with a pore size of $0.45 \mu \mathrm{m}$. The concentrations of nutrients were determined by spectrophotometric methods. Phosphates were determined by the DenigerAtkins method using tin chloride, ammonium ions
- by the indophenol method, nitrates - using salicylic sodium, nitrites - using the Griss reagent, and silica was measured as a yellow silicomolybdate complex (Rukovodstvo..., 2009).

\section{Results and discussion}

The data on the 2018-2019 measurements revealed the small concentrations of nitrates, phosphates and silica in the water from the pelagic zone of Lake Baikal, which increased with depth (Fig.). The average concentration of nitrates in the near-bottom area of the southern part of the lake was $0.64 \mathrm{mg} / \mathrm{l}$, of the central one $-0.69 \mathrm{mg} / \mathrm{l}$ and of the northern one $-0.65 \mathrm{mg} / \mathrm{l}$, and the average concentration of phosphates was 0.050 $\mathrm{mg} / \mathrm{l}, 0.067 \mathrm{mg} / \mathrm{l}$ and $0.047 \mathrm{mg} / \mathrm{l}$, respectively. The average concentration of silica in the near-bottom zone of the southern basin was $1.75 \mathrm{mg} / \mathrm{l}$, of the central one $-2.55 \mathrm{mg} / \mathrm{l}$ and of the northern one $-1.63 \mathrm{mg} / \mathrm{l}$. Inside the basins, the differences in the concentrations at the same depths of the layer below $200 \mathrm{~m}$ did not exceed $10 \%$, and in the near-bottom layer - $15 \%$. The nitrate concentration in the upper layer of water mainly decreased from May-June to late July and insignificantly increased by September. Notably, in September 2019, phytoplankton almost completely consumed phosphates in the upper layer of water of the pelagic zone. The silica concentration decreased by 20 $30 \%$ in late July and increased by September.

The spatial distribution of nitrates and phosphates in the pelagic zone (along the length of the lake) is uneven and depends on the intensity of the phytoplankton development in some areas of the lake. In all observation periods, the silica concentration

*Corresponding author.

E-mail address: hydrochem@lin.irk.ru (V.M. Domysheva)

(C) Author(s) 2020. This work is distributed under the Creative Commons Attribution 4.0 License. 


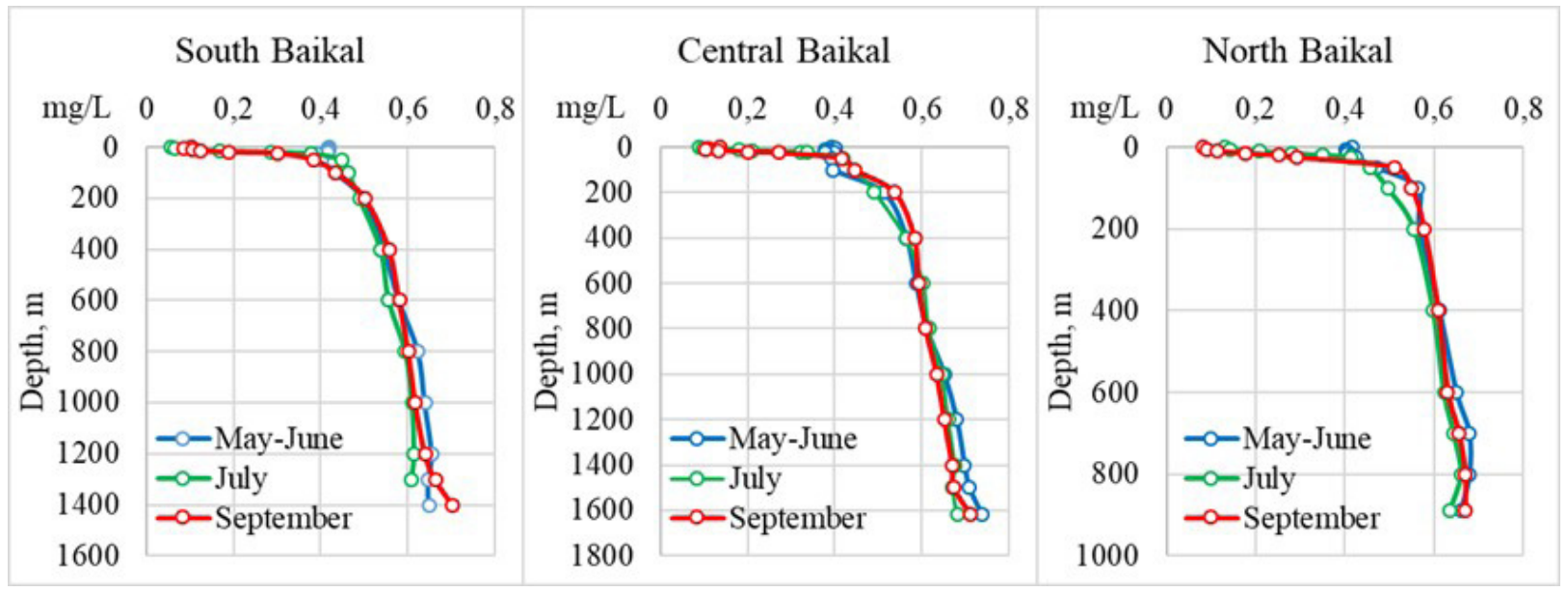

Fig. Vertical distribution of the nitrate concentration in Lake Baikal in 2019.

was higher in the northern basin due to its influx with waters from tributaries and a weaker development of the diatom complex (Popovskaya, 1991).

In late May and June we detected nitrites and ammonium ions in the upper $100 \mathrm{~m}$ layer at the concentrations close to the detection limits of the methods used. In July and September, we sometimes recorded a slight increase in their concentrations, and at some stations, the concentration of nitrites reached $0.030 \mathrm{mg} / \mathrm{l}$ and that of ammonium ions $-0.12 \mathrm{mg} / 1$.

Analysis of the interannual dynamics of nutrients (late May and June from 2007 to 2019) indicated that the weighted average concentration of silica and phosphates throughout the water column of the lake calculated taking into account the volume of layers did not change; in the upper $100 \mathrm{~m}$ layer, there was a trend towards a decrease in their concentration. For all basins of the lake, was a trend towards an increase in the nitrate concentration.

The studies carried out in the pelagic zone of Lake Baikal revealed that at the end of the summer, the concentration of phosphates in the upper layer of water decreased to the minimum, which was not previously recorded. In the deep part of the lake, there were no changes in the concentrations of nutrients. The interannual dynamics showed a slight increase in the weighted average concentration of nitrates in the lake.

\section{Acknowledgements}

This study was carried out within the framework of State Tasks Nos 0345-2020-0008 and AAAA-A17-117021310142-5, and with the partial support of Russian Foundation for Basic Research and the Government of the Republic of Buryatia of the Russian Federation (Grant No 18-45-030007)

\section{References}

Bondarenko N.A., Ozersky T., Obolkina L.A. et al. 2019. Recent changes in the spring microplankton of Lake Baikal, Russia. Limnologica 75: 19-29. DOI: 10.1016/j. jglr.2015.11.006

Izmest'eva L.R., Moore M.V., Hampton S.E. 2016. Lakewide physical and biological trends associated with warming in Lake Baikal. Journal of Great Lakes Research 42: 6-17. DOI: $10.1016 /$ j.jglr.2015.11.006

Kravtsova L.S., Izhboldina L.A., Khanaev I.V. et al. 2012. Disturbances of the vertical zoning of green algae in the coastal part of the Listvennichnyi Gulf of Lake Baikal. Doklady Biological Sciences 447: 350-352. DOI: 10.1134/ S0012496612060026

Popovskaya G.I. 1991. Phytoplankton of Lake Baikal and its long-term changes (from 1958 to 1990). Dr. Sc. Dissertation, Central Siberian Botanical Garden SB RAS, Novosibirsk, Russia. (in Russian)

Rukovodstvo po khimicheskomu analizu poverkhnostnykh vod sushi [Guidelines for the chemical analysis of land surface waters] Part 1. 2009. In: Boeva L.V. (Ed.). Rostov on Don: NOK. (in Russian)

Shimaraev M.N., Domysheva V.M. 2013. Trends in hydrological and hydrochemical processes in Lake Baikal under conditions of modern climate change. In: Goldman C., Kumagai M., Robarts R.D. (Eds.), Climatic change and global warming of inland waters. New-York, pp. 43-66. DOI: 10.1002/9781118470596

Timoshkin O.A., Bondarenko N.A., Volkova E.A. et al. 2014. Mass development of green filamentous algae of the genera Spirogyra and Stigeoclonium (Chlorophyta) in the coastal zone of Southern Baikal. Gidrobiologicheskiy Zhurnal [Hydrobiological Journal] 50: 15-26. (in Russian) 